\title{
Relation between dietary intake and nutritional status in cystic fibrosis
}

\author{
H Anthony, J Bines, P Phelan, S Paxton
}

\begin{abstract}
This study evaluated adherence to current dietary recommendations of children with cystic fibrosis and mild lung disease and their siblings by comparing energy intake. Fifty children ( 25 with cystic fibrosis) aged between 7 and 12 years completed the study. Energy intake was assessed by weighed dietary intake, resting energy expenditure was used to calculate recommended daily intakes. The children with cystic fibrosis had significant deficits in $Z$ scores for both height and weight compared with their siblings, but there was no difference in percentage of ideal weight for height. The cystic fibrosis group had a significantly higher energy intake per kilogram body weight per day but there was no difference in the percentage of energy derived from fat, protein or carbohydrate. Energy intake (per kg/day) and fat intake (g/kg) were both significant predictors of weight for height in the cystic fibrosis group. Targets for dietary management in cystic fibrosis should perhaps be related to fat intake per kilogram body weight.

(Arch Dis Child 1998;78:443-447)
\end{abstract}

Keywords: cystic fibrosis; dietary management; nutritional status

When cystic fibrosis was first described in the 1930 s malnutrition was accepted as an inevitable consequence of the disease process, and few patients survived their childhood. ${ }^{1}$ Improvements in treatment have resulted in the mean age of survival being 30 years for men and 25 years for women. ${ }^{2}$ The North American Cystic Fibrosis Association reports that in 1995, $25.2 \%$ of the American cystic fibrosis population weighed less than NCHS 5 th percentile. ${ }^{3}$ This continuing malnutrition demonstrates the need to improve nutritional management and to define optimal management strategies of patients with cystic fibrosis.

Survival largely depends on the rate of progression of lung disease. The gradual deterioration in pulmonary status is associated with a worsening in nutritional status, and patients with end stage disease are often malnourished. ${ }^{4}$ Poor nutritional status has been associated with reduced exercise tolerance in advanced cystic fibrosis. ${ }^{5}$ Whether a decline of pulmonary function is followed by malnutrition, or malnutrition is a precursor of respiratory function decline, remains unanswered. However, there is evidence that inadequate nutritional status early in life may result in poor lung development, ${ }^{6}$ and early impairment of lung growth may influence the progression of pulmonary disease. ${ }^{7}$

The causes of malnutrition and growth failure in cystic fibrosis are linked both to pancreatic insufficiency causing chronic energy loss via the stool, and an increase in energy requirement, which is probably concurrent with a decline in pulmonary function. ${ }^{8}$ A negative energy balance results if dietary intake fails to meet additional energy requirements.

The dietary management of patients with cystic fibrosis changed with the recognition of growth and survival advantages of those adhering to a high fat diet. ${ }^{9}$ Current dietary recommendations are based on the need to reach $120-150 \%$ of the recommended daily intake (RDI) for age. By maintaining a diet with a high percentage of fat ( $40 \%$ of energy) and carbohydrate (mainly from simple sources) ${ }^{1011}$ these goals may be achieved. Despite these recommendations, studies show that dietary intakes fall short of these targets, ${ }^{12-16}$ although they are achievable with intensive dietetic support. ${ }^{17}$ Previous studies have compared children with cystic fibrosis with normal children; we used healthy siblings as controls to take into consideration family influences on food choice and to ascertain whether children with cystic fibrosis are provided with higher fat intakes than their healthy siblings.

We evaluated adherence to current dietary recommendations within families by measuring the actual energy intake of children with cystic fibrosis and their healthy siblings. We assessed the impact of the composition of dietary energy on growth in children with cystic fibrosis and evaluated the current method of measuring dietary adequacy.

\section{Methods}

SUBJECTS

Children with cystic fibrosis aged between 7 and 12 years were graded according to their lung disease $\mathrm{e}^{18}$ and invited to participate if they met the following criteria: had mild lung disease (severity score less than grade 3), did not have diabetes or liver disease, did not receive overnight enteral feeding, and had a sibling aged between 7 and 12 years who did not have cystic fibrosis. All children had to be free from acute infection at the time of the study. Fifty children, 25 with cystic fibrosis, (14 boys and 11 girls, mean (SD) age 9.1 (1.2)) and 25 healthy siblings ( 12 boys and 13 girls, aged 9.8 (1.7)) were recruited, and all families completed the study within six months. Ethical approval was obtained from the ethics in 
Table 1 Nutritional status, resting energy expenditure, and dietary intake in 25 children with cystic fibrosis (CF) and 25 healthy siblings

\begin{tabular}{llll}
\hline & Children with CF & Healthy siblings & 95\% CI \\
\hline Z score height & $-0.33(0.9)$ & $0.48(1.0)$ & -1.3 to $-0.4^{\star}$ \\
$Z$ score weight & $-0.25(0.9)$ & $0.36(0.8)$ & -0.9 to $-0.3^{\star}$ \\
Ideal weight for height $(\%)$ & $0.98(0.12)$ & $0.99(0.12)$ & -0.1 to 0.1 \\
Body mass index $\left(\mathrm{kg} / \mathrm{m}^{2}\right)$ & $16.3(1.2)$ & $17.8(2.3)$ & -2.5 to $-0.5^{\star}$ \\
Measured REE $(\mathrm{kJ} / \mathrm{kg})(\mathrm{n}=24)$ & $181(23)$ & $146(39)^{\star}$ & -12.5 to $-3.7^{\star}$ \\
Respiratory quotient & $0.80(0.04)$ & $0.84(0.03)$ & -0.014 to 0.024 \\
Energy intake $(\mathrm{kJ} / \mathrm{kg})$ & $312(57)$ & $235(53)$ & -25 to $-12^{\star}$ \\
Percentage energy from: & & & \\
$\quad$ Fat & $37.4(4.0)$ & $36.8(4.1)$ & -8.9 to 27.6 \\
$\quad$ Carbohydrate & $48.8(4.6)$ & $48.3(4.8)$ & -2.5 to 1.7 \\
$\quad$ Protein & $13.9(1.7)$ & $13.8(2.0)$ & -1.0 to 0.7 \\
\hline
\end{tabular}

Values are means (SD).

${ }^{\star} \mathrm{p}<0.05$.

REE, resting energy expenditure.

human research committee of the Royal Children's Hospital, Melbourne. Parents were informed that the study aimed to investigate the nutritional status of children with cystic fibrosis but were not informed that dietary adherence was being investigated.

RESTING ENERGY EXPENDITURE

Resting energy expenditure (REE) was measured using a portable metabolic measurement cart that uses a ventilated hood system to measure inspired oxygen and expired carbon dioxide (Deltatrac; Datex, Helsinki, Finland). The machine was calibrated against standard gases before each test. The sibling pairs were asked to come to the hospital early in the morning after an overnight fast. After a 30 minute rest the ventilated hood was placed over their head. They were instructed to lie still during the period of the measurement. The metabolic monitor measured expired carbon dioxide and inspired oxygen at one minute intervals. The first five minutes were excluded from analysis, which continued until a steady state with less than $10 \%$ variation in REE for a minimum period of 25 minutes was reached. These readings were averaged to obtain the final REE. REE of one sibling pair was excluded from the final analysis because excessive movement of the healthy child resulted in a greater than $10 \%$ deviation in REE. Predicted REE was calculated using the equations of Schofield ${ }^{19}$; RDIs were calculated using the $\mathrm{FAO} / \mathrm{WHO} / \mathrm{UNN}$ report. ${ }^{20}$

\section{DIETARY INTAKE DATA}

We used a combination of the precise weighing and the weighed inventory method to discriminate between potentially small differences in dietary intake between siblings. ${ }^{21}$ Families were trained in food recording procedures, given

Table 2 Multiple regression of the relation among nutritional status, disease, and dietary variables in cystic fibrosis

\begin{tabular}{lcc}
\hline & $\beta$ & $p$ value \\
\hline Energy intake per kg $_{\text {FEV }_{1}}$ & 0.445 & 0.041 \\
Grade of disease $_{\text {Coefficient of fat absorption }}$ & 0.448 & 0.066 \\
REE \% above predicted & 0.195 & 0.409 \\
& -0.058 & 0.866 \\
\end{tabular}

$\mathrm{FEV}_{1}$, forced expiratory volume in one second; REE, resting energy expenditure.

$F=1.91, R^{2}(\operatorname{adj}) 15.8 \%, d f=5,19, p=0.14$. digital scales ( $0-1 \mathrm{~kg}$ in $1 \mathrm{~g}$ increments), and a food recording book for each child. The food intake of each sibling was recorded simultaneously within 14 days of REE measurement. Food intake records were obtained for seven consecutive days, including a school week. Families were telephoned on day 2 to check the food recording procedure, and were provided with a contact telephone number for additional queries. On completion of the food record, the family was either visited at home or came to the hospital, and each day of the food record assessed for completeness. ${ }^{22}$ Incomplete days were excluded from the nutrient analysis. Food records were coded and analysed using the Diet 1 program (Xyris Software, Brisbane, Australia). All aspects of the food recording procedure were completed by an accredited practising dietitian (HA).

FAECAL FAT EXCRETION

All patients with cystic fibrosis were pancreatic insufficient and completed a two day faecal fat collection during the weekend days of the food record. The number and type of pancreatic enzyme capsules taken with each food item were recorded. Faecal samples were frozen before transportation to the hospital where they were analysed using the method of Van de Kramer et $a l^{23}$ and the coefficient of fat absorption obtained.

\section{ANTHROPOMETRIC MEASUREMENTS}

All subjects were weighed in light clothing using a digital chair scale $(0.01 \mathrm{~kg}$ increments) after the REE measurement, and height was measured in $0.1 \mathrm{~cm}$ increments using a Holtain stadiometer (Dyfed, Wales). Weight and height were converted to $\mathrm{Z}$ scores for comparison with a normal population and to adjust for age and sex. Ideal weight for height was calculated using the formula described in the cystic fibrosis consensus report. ${ }^{11}$

\section{RESPIRATORY ASSESSMENT}

Forced expiratory volume in one second

$\mathrm{FEV}_{1}$ was measured by a trained technician using standard techniques. ${ }^{24}$

\section{Grade of pulmonary disease}

Pulmonary disease was graded according to the Holtzer score, which takes into account cough, sputum production, chest $x$ ray, and $\mathrm{FEV}_{1} \cdot{ }^{18}$

\section{STATISTICAL ANALYSIS}

Paired $t$ tests were used to compare observed with predicted variables between healthy and cystic fibrosis groups. Regression analysis was used to investigate relations between dependent and one or more independent variables; significance is defined as $\mathrm{p}<0.05$.

\section{Results}

GROWTH, REE, AND DIETARY INTAKE.

Children with cystic fibrosis were significantly shorter ( $Z$ score for height, 95\% confidence intervals (CI) -1.3 to -0.4$)$, and lighter ( $Z$ score for weight, $95 \%$ CI -0.9 to -0.3 ) than their siblings. There was no significant difference in percentage of ideal weight for 
Table 3 Correlation matrix between intake of nutrients per kilogram body weight, meeting the RDI for energy, and nutritional status

\begin{tabular}{rllll}
\hline \multicolumn{1}{c}{} & RDI & Fat & Protein & Carbohydrate \\
\cline { 2 - 5 } Fat & $0.64 \dagger$ & & & \\
Protein & $0.59 \dagger$ & $0.82 \dagger$ & & \\
Carbohydrate & $0.63 \dagger$ & $0.57 \dagger$ & $0.62 \dagger$ & \\
\%IWH & 0.29 & $0.46^{\star}$ & 0.22 & 0.29 \\
\hline
\end{tabular}

${ }^{\star} \mathrm{p}<0.05 ; \mathrm{tp}<0.005$.

$\mathrm{RDI}$, recommended daily intake, $\% \mathrm{IWH}$, pecentage ideal weight for height.

height (\%IWH) between the two groups. REE in children with cystic fibrosis was significantly higher than in their sibling controls (95\% CI -12.5 to -3.7$)$. Using the Schofield equation, the cystic fibrosis group differed significantly from predicted values (95\% CI 2.8 to 6.1 ) and, on average, REE was raised by $11 \%$ above predicted. The healthy siblings did not have a significantly different REE compared with predicted values ( $95 \% \mathrm{CI}-3.0$ to 3.1 ), average values being $102 \%$ of predicted.

Pancreatic insufficiency was well controlled, mean (SD) coefficient of fat absorption being $86(6.9) \%$ (range, 71-96\%, laboratory coefficient of variation 8.1).

After food records were assessed for completeness 44 subjects (88\%) had complete records for all seven days, three had complete records for six days, and three had records that were complete for two to five days. Although the children with cystic fibrosis had a significantly higher total energy intake per kilogram of body weight than their siblings $(95 \% \mathrm{CI}-25$ to -12 ), there was no significant difference in the proportion of energy derived from fat, carbohydrate or protein (table 1).

FACTORS AFFECTING NUTRITIONAL STATUS

The children with cystic fibrosis had $\mathrm{Z}$ scores for both height and weight lower than expected normal values. The US consensus report ${ }^{11}$ suggests that \%IWH is a suitable indicator of nutritional status in cystic fibrosis patients as it takes into account both weight and height; therefore, \%IWH was used as a measure of nutritional status. Simple regression indicated a significant positive association between energy intake per kilogram body weight and

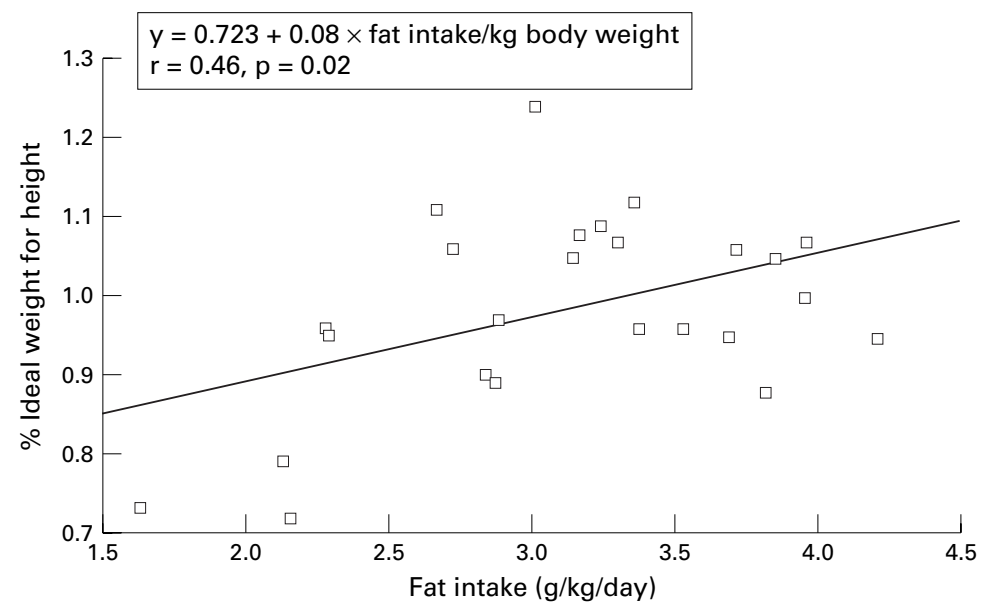

Figure 1 Percentage ideal weight for height related to fat intake per kilogram bodyweight. nutritional status in the cystic fibrosis group $(r=0.41, \mathrm{p}=0.04)$.

Multiple regression was performed to examine the relation between nutritional status, dietary intake, and disease variables in the cystic fibrosis group. The predictor variables were those shown by previous research most likely to affect nutritional status, and were entered all at once (table 2). After energy intake had been taken into account, addition of these predictor variables explained only a further $3.1 \%$ of the variance in nutritional status than when energy intake alone is considered. We recognise that this process is affected by both the relatively small sample size and the collinearity of the predictor variables, and the results were not significant overall.

\section{DIETARY COMPOSITION AND NUTRITIONAL}

STATUS

We explored the impact of current dietary recommendations of having a high percentage of fat in the diet. With the percentage of energy derived from fat, carbohydrate, and protein as the predictor, variables were entered at once with \%IWH as the dependent variable, none of the variables in the regression was found to be significantly related to nutritional status $\left(\mathrm{F}=1.9, \mathrm{df}=4,20, \mathrm{R}^{2}\right.$ (adj) $\left.12.5 \%, \mathrm{p}=0.15\right)$. The coefficient of fat absorption was initially included to account for energy loss in the stool but was removed from the model as it did not affect the regression.

The proportion of macronutrients in the diet was not significant in predicting nutritional status but the total energy intake was important, therefore, the amounts of fat, protein, and carbohydrate per kilogram of body weight were entered into the regression. The three variables together explained $20.8 \%$ of the variance $(\mathrm{F}=3.10, \mathrm{df}=3,21, \mathrm{p}=0.04)$. Fat intake per kilogram was a significant independent predictor $(p=0.02, r=0.46)$ (fig 1$)$.

\section{ACHIEVING RECOMMENDED ENERGY INTAKES}

Mean (SD) daily energy intake was 8.9 (1.4) $\mathrm{MJ}$ in the cystic fibrosis group and 8.2 (1.1) MJ in the sibling group. Mean RDI was 8.9 (1.1) MJ for the cystic fibrosis patients and 8.6 (1.6) MJ for their siblings. Eleven of the children with cystic fibrosis achieved an energy intake equivalent or above their RDI; four achieved an energy intake of $>120 \%$ of the RDI.

As few children met the target of $120 \%$ RDI, we investigated which dietary components were associated with achieving the RDI. The intake of macronutrients per kilogram of body weight was found to be significantly related to nutritional status, therefore we used multiple regression to assess the relation between meeting the RDI and dietary components expressed as $\mathrm{g} / \mathrm{kg}$ of body weight. This explained $43.2 \%$ of the variance $(\mathrm{F}=7.1, \mathrm{df}=3,21$, $\mathrm{p}=0.002$ ), with only carbohydrate approaching significance as an independent predictor $(p=0.07)$. These results are affected by the high collinearity between the predictor variables, which although expected, makes the interpretation of these dietary variables 
difficult, especially with the relatively small sample size (table 3). By entering each predictor variable individually, using simple regression, it is clear that all three dietary components are important in meeting the RDI: carbohydrate $\left(\mathrm{R}^{2}\right.$ (adj) $40.2 \%, \mathrm{~F}=15.5, \mathrm{df}=1$, $23, \mathrm{p}=0.007)$, fat $\left(\mathrm{R}^{2}(\mathrm{adj}) 31.4 \%, \mathrm{~F}=12.3\right.$, $\mathrm{df}=1,23, \mathrm{p}=0.002)$, and protein $\left(\mathrm{R}^{2}(\mathrm{adj})\right.$ $38.0 \%, \quad F=15.7, \quad d f=1,23, p=0.0006)$. Multiple regression used to investigate whether bivariate correlations could be increased by using more than one predictor variable did not result in any gains in $\mathrm{R}^{2}$. Therefore, it was not possible to determine the independent effects of the three components.

There was no significant correlation between meeting the RDI and \%IWH but simple regression demonstrated a significant and positive relation between energy intake per kilogram body weight and \%IWH $(r=0.41$, $\mathrm{p}=0.045)$.

\section{Discussion}

Our study focused on children with cystic fibrosis who were not considered at nutritional risk as they had mild lung disease and were well nourished (if \%IWH is used as the sole criterion). However, if $\mathrm{Z}$ scores for either height or weight are taken as indicators of nutritional status, this group of children have significant deficits in both measurements compared with their healthy siblings, which are lower than would be expected from normal values. The siblings in our study have slightly higher $\mathrm{Z}$ scores for both height and weight than expected. This may be because their diet allows for their maximum genetic potential to be reached. If this is the case, the proportional deficit between children with cystic fibrosis and their siblings assumes greater significance. To test this would require a healthy non-related control group matched for socioeconomic status and ethnicity. The growth comparison available in our study demonstrates that the identification of nutritional risk depends on the reference criteria applied. Lai and colleagues ${ }^{25}$ reported a similar phenomenon in a large group of cystic fibrosis patients in the United States; they found poor agreement between different growth failure criteria. Our study indicates that even at this relatively early age (mean 9.2 years), cystic fibrosis patients have compromised growth compared to healthy children, and they have proportional deficits in height and weight. Relying on \%IWH, as the US consensus report suggests, may fail to identify children who are stunted, and monitoring $\mathrm{Z}$ scores for height and weight in conjunction with \%IWH would be beneficial.

Higher REE in the cystic fibrosis children is consistent with previous studies. ${ }^{82627}$ The mean $11 \%$ increase in REE from predicted values, although significantly greater than the norm, is not an insurmountable barrier to achieve energy balance. It should be possible to compensate for this increase in energy requirement by augmenting the diet. The use of standard predictive formulae, such as the Schofield equation, has limited application in this clinical group. The addition of regular measurement of REE combined with analysis of dietary intake may allow children with cystic fibrosis who are consistently failing to meet their increased energy needs to be monitored efficiently, and their specific nutritional needs addressed appropriately. The use of RDIs based on a predicted REE does not allow for the additional individual energy required in cystic fibrosis. Our study questions the benefit of basing energy goals in this population on RDIs, as we did not find a relation between meeting the RDI and nutritional status.

Although the children with cystic fibrosis had a total energy intake significantly higher than their siblings, it was not sufficient to maintain age and sex appropriate growth rates. The percentage of energy from macronutrients did not differ between the two groups, which implies that the children with cystic fibrosis eat more of all foods rather than just high fat foods. Children with cystic fibrosis should get $40 \%$ of their energy from fat, ${ }^{10}{ }^{16}$ but this was not achieved in the children in our study. The percentage of fat in the diet was similar to other reported studies in cystic fibrosis ${ }^{12-16}$ and about the same as the average intake in Australia. ${ }^{28}$ We did not expect to find that the percentage of energy from macronutrients, particularly fat, would not be relevant in the prediction of $\%$ IWH. We did find a significant relation between \%IWH and fat intake per kilogram of body weight, which concurs with the study by Collins et al who suggested that a fat target would be a better guide for dietary recommendations. ${ }^{29}$

We have demonstrated the importance of nutrition in cystic fibrosis. After adjusting for disease variables, dietary energy intake per kilogram of body weight is an important predictor of nutritional status. Although regression analysis does not prove a causal relation, it seems that dietary energy intake is a valuable indicator of nutritional status in cystic fibrosis patients.

A goal for dietary intake based on actual body weight may be beneficial. A fat intake target based on the patient's weight may help define energy goals better than current practice, which is neither achieved nor may be optimal. Fat intake goals would also enable pancreatic enzyme dosage to be targeted effectively and distributed according to intake as well as body weight. ${ }^{3031}$

Pancreatic insufficiency has been shown to have a detrimental effect on nutritional status and survival. ${ }^{32}$ All our patients had pancreatic insufficiency but the coefficient of fat absorption did not appear to be a major influence on nutritional status. This may be because adherence to enzyme replacement was good and faecal energy loss was not excessive.

We are currently investigating why children with cystic fibrosis have the same percentage of fat in their diet as their healthy siblings. Possible explanations may be that children prefer to eat high carbohydrate foods, or that the requirement to take additional pancreatic enzymes with fatty foods leads to a reduced intake. Parents may be reluctant to give additional fat in the belief that it is not healthy, 
and that the provision of a family diet takes precedence over a therapeutic diet. Clearly there is much to be learnt to define optimal dietary advice for cystic fibrosis patients, and to define the relation between dietary components and indices of nutritional status.

This project was supported by an Australian Research Council Small Project Grant and the Royal Children's Hospital Research Foundation. We thank Drs A Olinsky, C Robertson, and P Robinson for access to their patients and Ms Lyndal Bond, department of clinical epidemiology and biostatistics, Royal Children's Hospital for statistical advice.

1 Anderson DH. Cystic fibrosis of the pancreas and its relation to disease. A clinical and pathological study. $A m \mathcal{F}$ Dis Child 1938;56:344-7.

2 FitzSimmons SC. The changing epidemiology of cystic fibrosis. F Pediatr 1993;122:1-9.

3 Cystic Fibrosis Foundation. Patient registry 1995. Annual data report. Bethesda: Cystic Fibrosis Foundation, 1996.

4 Bakker W. Nutritional state and lung disease in cystic fibrosis. Neth $\mathcal{F}$ Med 1992;41:130-6.

5 Marcotte JE, Canny GJ, Grisdale R, Desmond K, Corey M, Zinman R, et al. Effects of nutritional status on exercise performance in advanced cystic fibrosis. Chest 1986;90: performan.

6 Inselman LS, Mellins RB. Growth and development of the lung. F Pediatr 1981;98:1-15.

7 Thomson MA, Quirk P, Swanson CE, Thomas BJ, Holt TL Francis PJ, et al. Nutritional growth retardation is associated with defective lung growth in cystic fibrosis: a preventable determinant of progressive pulmonary dysfunction. Nutrition 1995;11:350-4

8 Fried MD, Durie PR, Tsui LC, Corey M, Levison H, Pencharz PB. The cystic fibrosis gene and resting energy expenditure. F Pediatr 1991;119:913-16.

9 Corey M, McLaughlin FJ, Williams M, Levison H. A comparison of survival, growth, and pulmonary function in patients with cystic fibrosis in Boston and Toronto. 7 Clin Epidemiol 1988;41:583-91.

10 MacDonald A. Nutritional management of cystic fibrosis. Arch Dis Child 1996;74:81-7.

11 Ramsey BW, Farrell PM, Pencharz PB, and the Consensus Committee. Nutritional assessment and management in cystic fibrosis: a consensus report. Am f Clin Nutr 1992;55: 108-16.

12 Kawchak DA, Zhao H, Scanlin TF, Tomezsko JL, Cnaan A, Stallings VA. Longitudinal, prospective analysis of dietary intake in children with cystic fibrosis. F Pediatr 1996;129: $119-28$.

13 Bentur L, Kalnins D, Levison H, Corey M, Durie PR. Dietary intakes of young children with cystic fibrosis: is there a difference? f Pediatr Gastroenterol Nutr 1996;22: $254-8$
14 Tomezsko JL, Stallings VA, Scanlin TF. Dietary intake of healthy children with cystic fibrosis compared with normal healthy children with cystic fibrosis compare

15 Macdonald A, Kelleher JM, Littlewood JM. A normal fat diet for cystic fibrosis: is a dietitian still needed? Scand $\mathcal{F}$ Gastroenterol 1988;23(suppl 143):157-9.

16 Bell SC, Durie PR, Forstner GG. What do children with cystic fibrosis eat? F Pediatr Gastroenterol Nutr 1984;3(suppl 1):S137-46.

17 Hubbard VS, Mangrum PJ. Energy intake and nutrition counseling in cystic fibrosis. 7 Am Diet Assoc 1982;80:12731.

18 Holzer FJ, Olinsky A, Phelan PD. Variability of airways hyper-reactivity and allergy in cystic fibrosis. Arch Dis Child 1981;56:455-9.

19 Schofield WN. Predicting basal metabolic rate, new standards and review of previous work. Hum Nutr: Clin Nutr 1985;39(suppl 1):5-41.

20 Energy and protein requirements. Report of the FAO/ WHO/UNN Expert Consultation. Technical report series 724. Geneva: WHO, 1985.

21 Marr JW. Individual dietary surveys: purposes and methods. World Review of Nutrition and Diet 1971;13:105-64.

22 Garrahie EJ, Humphrey KF, Witschi JC, Stephenson WP, Ellison RC. The value of debriefing mothers of 3- to 7 -year-old children when analyzing children's food diaries. f Am Diet Assoc 1991;91:710-1.

23 Kramer Van de JH, Huinink $\mathrm{H}$, Weyers $\mathrm{H}$. A rapid method for determining fat in the feces. F Biol Chem 1949;177:347-55.

24 Quanjer PhT. Standardized lung function testing. Bulletin European de Physiogie Respiratoire 1983;(suppl 5):19-21.

25 Lai H, Kosorok M, Sondell S, Farrell P. Characterization of growth in children with cystic fibrosis [abstract]. Pediatr

26 Bell SC, Saunders MJ, Elborn JS, Shale DJ. Resting energy expenditure and oxygen cost of breathing in patients with cystic fibros. Thorax 1996;51:126-31.

27 Vaisman N, Pencharz PB, Corey M, Canny GJ, Hahn E. Energy expenditure of patients with cystic fibrosis. F Pediatr 1987;111:496-500.

28 Department of Community Services and Health. National dietary survey of school children (aged 10-15 years) nutrient intakes. Canberra: Australian Government Publishing Service, $1989 ; 2$

29 Collins C, O'Loughlin E, Henry R. Fat gram target to achieve high energy intake in cystic fibrosis. $\mathcal{F}$ Paediatr Child Health 1997;31:142-7.

30 Borowitz DS, Grand RJ, Durie PR. Use of pancreatic enzyme supplements for patients with cystic fibrosis in the context of fibrosing colonopathy. Consensus committee. $\mathcal{F}$ Pediatr 1995;127:681-4.

31 Constantini D, Paodan R, Curcio L. The management of enzymatic therapy in cystic fibrosis patients by an individualised approach. F Pediatr Gastroenterol Nutr 1988;7(suppl 1):S36-9.

32 Gaskin K, Gurwitz D, Durie P, Corey M, Levison H, Forstner G. Improved respiratory prognosis in patients with cystic fibrosis with normal fat absorption. I Pediatr 1982;100:857-62. 